
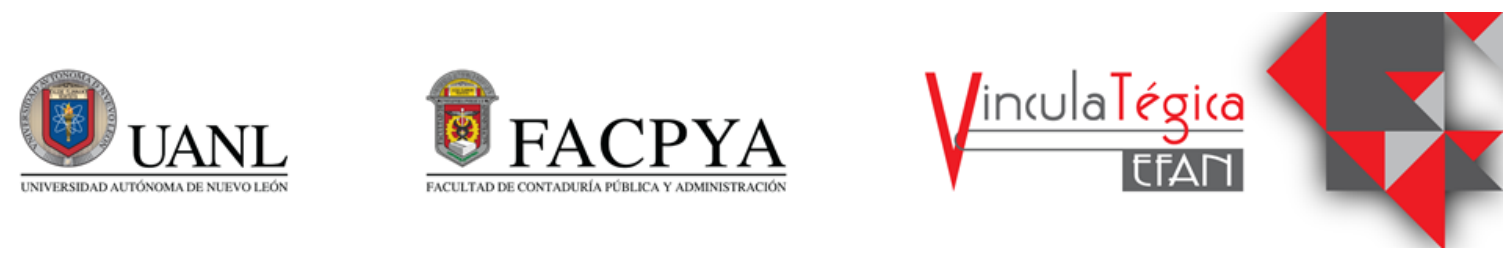

\title{
La política hacendaria en México, finanzas públicas y competitividad
}

\author{
Héctor Fabián Gutiérrez Rangel ${ }^{1}$, Artemio Jiménez Rico ${ }^{2}$ y Rafael Espinosa Mosqueda ${ }^{3}$ \\ ${ }^{1}$ Universidad de Guanajuato, fabiangr@ugto.mx, Fracc. El Establo S/N Sede Marfil,4734598281 \\ ${ }^{2}$ Universidad de Guanajuato, A.jimenezrico@ugto.mx, Fracc. El Establo S/N Sede Marfil,4734598281 \\ ${ }^{3}$ Universidad de Guanajuato, asesorneg@yahoo.com.mx, Fracc. El Establo S/N Sede Marfil,4734598281
}

Información del artículo revisado por pares

Fecha de aceptación: junio-2021

Fecha de publicación en línea: diciembre-2021

DOI: https://doi.org/10.29105/vtga7.2-64

\begin{abstract}
Resumen
La Organización para la Cooperación y el Desarrollo Económicos (OCDE) presentó el Estudio Económico de México donde se analizan las perspectivas de crecimiento económico. En este sentido las condiciones a nivel mundial han mejorado derivado del avance que se tienen en el esquema de vacunación, se prevé que el crecimiento del Producto Interno Bruto (PIB) sea del 5.6\%. Asimismo, un escenario al alza mejoraría las condiciones de competitividad si la producción de dosis y distribución se acelera con una mejor coordinación global y la anticipación a las nuevas mutaciones del virus; caso contrario en un escenario a la baja la confianza empresarial y el gasto de los consumidores se vería afectado por la fata de vacunas. En este sentido para México se vislumbra un crecimiento del PIB real del $4.5 \%$ respecto al año anterior que fue de $-8.5 \%$ debido a los efectos de la pandemia. La presente investigación presenta un estudio exploratorio y documental a partir de datos empíricos sobre la situación actual que guarda la política hacendaria en México y de qué manera a afectado en las finanzas públicas y la competitividad de los estados. Los resultados muestran que México cuanta con
\end{abstract}

Abstract

The Organization for Economic Cooperation and Development (OECD) presented the Economic Study of Mexico where the prospects for economic growth are analyzed. In this sense, conditions worldwide have improved as a result of the progress in the vaccination scheme, it is expected that the growth of the Gross Domestic Product (GDP) will be $5.6 \%$. Likewise, an upward scenario would improve competitive conditions if dose production and distribution is accelerated with better global coordination and anticipation of new virus mutations; Otherwise, in a downward scenario, business confidence and consumer spending would be affected by the lack of vaccines. In this sense, for Mexico, a real GDP growth of $4.5 \%$ is foreseen compared to the previous year, which was $-8.5 \%$ due to the effects of the pandemic. This research presents an exploratory and documentary study based on empirical data on the current situation of tax policy in Mexico and how it has affected public finances and the competitiveness of the states. The results show that Mexico has a solidity in its public finances derived from a fiscal policy that has made it possible to make collection systems more efficient, broaden the taxpayer base, increase collection and less dependence on oil revenues. On the other hand, the average 
una solidez en sus finanzas públicas derivado de una política hacendaria que ha permitido eficientar los sistemas recaudatorios, ampliar la base de contribuyentes, el incremento de la recaudación y menor dependencia de los ingresos petroleros. Por otra parte, el índice de competitividad promedio a nivel nacional se ubicó en 45.64 de 100 puntos según el Instituto Mexicano para la competitividad A.C.

Palabras clave: Política hacendaria; Finanzas públicas; Competitividad.

\section{INTRODUCCIÓN}

La situación económica mundial se encuentra en recuperación debido a la cobertura de vacunación, que ha propiciado la reactivación de actividades empresariales y el consumo. Principalmente, el crecimiento de la economía de los Estados Unidos de Norte América (EUA) tendrá un impacto positivo para México por su dependencia económica con el país vecino. México país miembro de la Organización para la Cooperación y el Desarrollo Económicos (OCDE) tiene que asumir compromisos que permitan mejorar la situación económica y el bienestar social. En el sexenio anterior, se llevaron a cabo diversas reformas estructurales como la fiscal, educativa, financiera y energética. Sin embargo, la situación económica a nivel mundial no ha permitido ver un impacto claro en el crecimiento y desarrollo económico del país, primeramente, previo a la pandemia por las tensiones comerciales entre Estados Unidos de Norte América (EUA) y China han propiciado un bajo crecimiento en el comercio mundial según la OCDE y en segundo lugar la llegada de la pandemia que colapsó las economías. Sin duda la situación es compleja, pero a medida que EUA se vaya recuperando, México tendrá que implementar diversas estrategias para ser competitivo ante la nueva normalidad.

En diciembre de 2018 tomó protesta la nueva administración encabezada por el presidente Andrés Manuel López Obrador, Dicho cambio trae consigo nuevas políticas públicas en aras de propiciar un crecimiento competitiveness index at the national level was 45.64 out of 100 points according to the Mexican Institute for Competitiveness A.C.

Keywords: Finance policy; Public finances; Competitiveness JEL: E62; M48.

económico y mejorar la calidad de vida de los sectores vulnerables en extrema pobreza.

En los criterios de política económica 2019, se señalan los compromisos de no incrementar los impuestos, de garantizar la estabilidad macroeconómica y de mantener las finanzas públicas sanas. Lo anterior, trae consigo cambios sustantivos en reasignaciones al presupuesto, es decir, la eliminación de gastos considerados innecesarios, eliminación de programas asistenciales cuyo reparto de recursos se hacía de forma discrecional y la eliminación y fusión de programas que se consideraron duplicados. En los primeros meses de ejercicio del nuevo gobierno y aunado al entorno económico de la economía mundial no se han percibido los beneficios de los cambios en la política pública, al contrario, la economía no ha crecido al ritmo esperado y algunas calificadoras de riesgo han optado por asignar calificaciones bajas a México.

Derivado del contexto adverso en la economía, en este artículo se hace un análisis de la política hacendaria con la finalidad de generar alternativas de mejora para seguir generando competitividad en las empresas y en el largo plazo dichas estrategias permitan coadyuvar a contar con un mejor desarrollo económico para México.

\section{MARCO TEÓRICO \\ 2.1 Política hacendaria}

Durante los últimos años el desempeño de la actividad económica ha sido positivo a pesar de un entorno global caracterizado por un grado alto de incertidumbre debido a los 
efectos de la pandemia y volatilidad financiera. Una de las funciones principales del Banco de México y de la Secretaría de Hacienda y Crédito Público (SHCP) es coadyuvar a mantener la estabilidad económica del país, preservando el valor de la moneda nacional a lo largo del tiempo y generar políticas fiscales que garanticen el uso eficiente del gasto público entre otras funciones. Lo anterior, permite contribuir a mejorar el bienestar de los mexicanos, a través de la aplicabilidad de una adecuada política monetaria. Una vez establecida la política monetaria por el gobierno federal, se trabajó en la propuesta del paquete económico para el ejercicio fiscal 2021 cuya finalidad es el garantizar el fortalecimiento de las finanzas públicas optimizando el ejercicio del presupuesto de tal forma que se garanticen los servicios de salud, procurando una recuperación económica sostenida y mejorar las condiciones de vida de la mayoría de la población.

La política hacendaria emitida por la SHCP es sin duda un factor importante en el crecimiento económico del país. En este sentido, el reconocimiento de un menor crecimiento por esta secretaría en 2019 de un $2 \%$ al $1.6 \%$ y la proyección en 2020 a $1.9 \%$ sin incremento de impuestos, trae consigo un trabajo más eficiente de las políticas públicas y fiscales. Un entorno económico mundial no favorable da señales de mayores recortes en el gasto público. Es importante, que dichos recortes se apliquen al gasto corriente y no en la inversión y que el gobierno recaude vía impuestos locales como el predial y la tenencia que son más fáciles de recaudar (Serrano, 2019). Aunque no es la única alternativa, pero sin duda la política hacendaria es el principal instrumento que tienen los gobiernos para impulsar la inversión y el crecimiento económico.

Es importante conceptualizar los tipos de política hacendaria que puede implementar el gobierno mexicano. Ortiz (2014) la define como una rama de la política económica que configura el presupuesto del Estado como variable de control para asegurar la estabilidad económica a través de la creación de empleos y evitar situaciones de inflación.
De tal forma, que el presupuesto del Estado conformado por el gasto público está orientado a satisfacer los servicios básicos de la sociedad tales como el transferir dinero a personas que no reciben ningún servicio a cambio, ayudas sociales o apoyos por desempleo, servicios de salud, seguridad y educación entre otros.

En un reporte emitido por la UNAM (2012) explican que la política hacendaria se puede comprender como el conjunto de medidas relativas al régimen tributario, al gasto público, al endeudamiento y a las situaciones financieras y a su manejo, por parte de los organismos públicos en todos sus niveles.

Para el cobro de dichos impuestos, el Estado cuenta con un sustento jurídico que emana de la Constitución Política de los Estados Unidos Mexicanos donde se establecen los lineamientos bajo los cuales se organiza la Nación y la facultad para el cobro de contribuciones. Además, el artículo 32 fracción IV de la constitución establece la obligación de los ciudadanos de contribuir al gasto público. De esta forma, el gobierno genera ingresos por impuestos federales, estatales y municipales; la recaudación que realiza el Estado a través de convenios con la federación permite que el recurso se quede y no se vaya a la Federación con la finalidad de generar sus propios recursos y estos sean canalizados de manera eficiente a las necesidades locales.

En la figura 1 se puede observar el ingreso por concepto de impuestos de la Ley de Ingresos de la Federación, teniendo un incremento porcentual del año 2018 a 2019 del $12 \%$, del año 2019 a 2020 del $6 \%$ y sólo el $1 \%$ de incremento del 2020 para el 2021 por el efecto de la pandemia. Lo que indica que la reforma fiscal de 2014 y los esquemas de fiscalización por parte de la autoridad, paulatinamente han mejorado los ingresos por el concepto de impuestos. Sin embargo, México como miembro de la OCDE aún se encuentra por debajo del promedio en la recaudación de ingresos derivado de los impuestos; una de las principales razones es su economía informal que representa el 23\% del Producto Interno Bruto (PIB). 
Por otra parte, Rudiger, Dornbusch y Fischer (1995) hacen referencia a dos tipos de política hacendaria. La primera, conocida como expansiva, que se refiere al momento en el que se genera un déficit en los presupuestos del Estado, es decir, cuando el gasto público es mayor que los ingresos y el gobierno hace uso de la emisión de deuda pública para financiar sus proyectos. Lamentablemente, muchas veces se abusa de esta figura canalizando dichos préstamos a programas sociales no productivos. Para aplicar dicha política existen dos mecanismos; el aumento en el gasto público con la finalidad de aumentar la producción y reducir el paro o bien la disminución de impuestos para aumentar el gasto privado, lo que incrementa el consumo y una mayor inversión de las empresas, lo que se conoce como una mayor demanda económica y la creación de empleos.

La segunda, es conocida como la política hacendaria restrictiva $y$ hace referencia a cuando se genera un superávit en los presupuestos del Estado, es decir, cuando el gasto público es inferior a los ingresos fiscales y los mecanismos utilizados son contrarios a la política anterior; se reduce el gasto público con la finalidad de disminuir la demanda y en consecuencia la producción o bien reducir el gasto privado subiendo los impuestos para que los ciudadanos tengan una renta menor por los que disminuye su consumo y la demanda económica. Este tipo de política hacendaria se aplica cuando hay un periodo de excesiva expansión y es necesario frenarla para evitar incremento generalizado los precios mejor conocido como inflación. Por lo anterior, es importante implementar la política hacendaria adecuada para el logro de un pacto social más equitativo y con mayor inclusión. El reto del gobierno es que la ciudadanía tenga una cultura del pago de contribuciones y hacer conciencia de los beneficios que tendrían a través de los bienes y servicios ofertados por el gobierno. Lamentablemente, por cultura muchos de los mexicanos perciben el pago de impuestos como un castigo y no como un beneficio, además de percibir a la autoridad hacendaria como un ente que únicamente se preocupa por el cobro de impuestos.
En otros estudios Chamley (1986) demostró que la política hacendaria óptima consistiría en gravar con tasas muy elevadas las rentas de capital en los primeros periodos, mientras que en el largo plazo el tipo impositivo debería ser nulo, siendo las rentas del trabajo las únicas que deberían gravarse en el largo plazo. Sin embargo, en otros contextos, como modelos con incertidumbre, modelos de crecimiento endógeno $\mathrm{o}$ modelos de generaciones solapadas, estos resultados se mantienen sólo bajo ciertos supuestos que, en algunos casos, pueden ser muy restrictivos.

En cambio, Izunza y Sánchez (2019) realizaron un estudio sobre los límites de la política hacendaria para promover el desarrollo en México y concluyeron que una disciplina fiscal no es suficiente para lograr la estabilidad económica del país, porque la economía refleja serios límites de crecimiento y de generación de empleo. Así mismo, señalan que la disciplina fiscal encuentra su límite en el sistemático desequilibrio fiscal por la contratación permanente de deuda. Lo que demuestra que el equilibrio fiscal, tan expuesto en el discurso oficial y en las estadísticas, no se mantiene neutral a la política hacendaria contracíclica, ya que mantiene un papel restrictivo para las finanzas públicas. El déficit nulo o equilibrio fiscal como condición, no garantiza el crecimiento estable y sostenido, ni tampoco la creación de empleos.

Martínez y Torres (2017) manifiestan que México no ha hecho lo suficiente en solucionar las distorsiones fiscales y la carga que imponen al mercado laboral. Además, consideran que la falta de participación de los ciudadanos en el sistema fiscal ha causado un debilitamiento en el contrato gobierno y ciudadanía. Hacen mención que el contrato social es un acuerdo implícito entre los ciudadanos de un país y su Estado. En la manera en que existan regímenes fiscales eficientes donde el ejercicio del gasto público garantice un acceso a los derechos básicos con calidad se tendrá un mayor fortalecimiento con la sociedad. Por otro, lado la tasa de informalidad laboral publicada por el INEGI (2019) del 56.9\% sigue representando un grave problema para la economía mexicana. 
Un dato relevante por cada 100 pesos que se generan en el país, 77 salen de trabajos formales y el resto, 23 pesos, de la economía informal; a pesar de ello más de la mitad de los mexicanos están empleados en actividades no reguladas o bien en empleos que no generan prestaciones, apoyos económicos, ni otro incentivo marcado en la ley, informó el Instituto Nacional de Geografía y Estadística (INEGI, 2018). Lo anterior, afecta sustantivamente la economía de un país debido a la falta de formalidad que no permite contar con una base suficiente que contribuya al gasto público.

\subsection{Competitividad}

Cuando se habla de competitividad se puede hacer referencia a varios conceptos. Para efectos de esta investigación, se abordó el enfoque desde la perspectiva de qué tan competitivo es México para la atracción de inversión, en el manejo de sus finanzas públicas, la política pública, la disciplina fiscal y el ambiente de los negocios. Lo anterior, permitió conocer los factores que pueden influir en la competitividad de los estados y como a través de la política hacendaria pueden ser afectados o bien beneficiadas según el entorno económico en que se encuentre el país. Un concepto de competitividad es aquel abordado a nivel micro teniendo como unidad de análisis las empresas y otro a nivel macro considerando los agentes económicos y como unidad el análisis de los territorios (Annoni y Kozovska, 2010). En el plan microeconómico tiene su origen en las teorías del comercio internacional centrado en el enfoque de las ventajas absolutas de Adam Smith (1776) y las ventajas comparativas de Ricardo (1817) citados por Huber y Mungaray (2014) según los cuales las naciones que producen mayores bienes para el consumo y estos son intercambiados en economías abiertas, elevan su bienestar al ganar mercados y obtener mayores ganancias, gracias a la reducción de costos empleados en los procesos productivos. Una vez que se logran posicionarse en los mercados internacionales y en sus procesos productivos hacen uso de tecnología innovadora y se desplazan de contar con ventajas comparativas a economías de escala.
Por otro lado, considerando el plano macroeconómico no basta con la productividad, el comercio exterior y los bajos costos para medir la competitividad, también son considerados otros factores tales como la innovación, la aplicación de la ciencia y el desarrollo tecnológico, el capital humano, la cultura, las nuevas formas de organización empresarial, el entorno institucional y la promoción económica de los territorios, lo cual permite el fácil acceso a mercados internacionales a un buen nivel competitivo; contribuyendo de esta forma mejorar el bienestar social de un país. En palabras de Porter citado en Pinzón y Dary (2014), la competitividad de una nación depende de la capacidad de su industria para innovar y mejorar.

Las empresas consiguen ventajas competitivas mediante innovaciones. En este sentido, abordaremos la conceptualización de Corona (2011) el cual menciona que la competitividad es una variable multifactorial que se compone de formación empresarial, prácticas administrativas, laborales y productivas, la innovación (interna o externa) y el progreso tecnológico. Como se puede observar su enfoque va más al sector empresarial, sin embargo, hay que resaltar que la competitividad es el resultado de múltiples factores.

En los últimos años en México se ha venido trabajando para ser del país un destino competitivo para la inversión, el desarrollo de negocios y la productividad en un entorno internacional con una economía en desaceleración. En este sentido la OCDE (2018) reconoce la utilidad de estos índices con sus diferentes perspectivas, herramientas para el pulso económico y la competitividad de los territorios, pero también afirma que pueden existir desventajas al respecto, si dichos índices no están bien construidos de acuerdo con la realidad que vive cada país y puede afectar considerablemente en la toma de decisiones.

Si bien, las distintas definiciones relativas a la competitividad tienen un marco de referencia microeconómico, hoy en día incluyen elementos macroeconómicos, socioeconómicos, políticos y culturales que 
también influyen en el desempeño de las empresas y en el nivel de vida de la población, debido a que reconocen la correlación entre la competitividad de los países y los niveles de vida de su población.

Por otro lado, el Instituto Mexicano para

la competitividad (2021) mide la competitividad de los estados a través de la capacidad de generar, atraer y retener talento e inversión; lo que se traduce en mayor productividad y bienestar para los habitantes.

\section{MÉTODO}

La metodología utilizada en esta investigación es cualitativa documental, ya que permiten dar explicación a diferentes concepciones del objeto investigado. En este caso se buscó fundamento teórico de la política hacendaria, las finanzas públicas y la competitividad consultando diversos estudios. Además, se contrastó información de fuentes oficiales las cuales fueron consultadas en bases de datos académicas reconocidas.

Lo anterior, permitió conocer las estadísticas sobre el comportamiento de la competitividad en México, así como los efectos de los ingresos tributarios y la situación de las finanzas públicas. De esta forma al hacer uso de la estrategia de triangulación, se buscó explicar la realidad de México en los aspectos de la política hacendaría y competitividad. Una vez analizados desde diferentes perspectivas dichos conceptos se hace un aporte para contribuir a una mejor política hacendaria en el rubro de los impuestos en un entorno económico mundial no favorable para la economía mexicana.

Además, se utilizaron datos de índices de competitividad de diversas instituciones para confrontarlos con los resultados de las finanzas públicas que cuenta el país y de esta manera identificar áreas de oportunidad y crecimiento para México.

\subsection{Supuestos de la investigación}

Con el objeto de brindar propuestas para mejorar la situación económica del país ante una nueva normalidad y mejorar la competitividad del país desde la perspectiva de una reforma fiscal se realzan las siguientes propuestas:

Proposición 1.

Un equilibrio entre la política hacendaria restrictiva y expansiva permitiría mejorar la situación económica del país y generar mayor competitividad en el país.

Proposición 2.

La implementación de estrategias fiscalizadoras para reducir la economía informal mejoraría la recaudación de impuestos y la situación económica del país. Proposición 3.

Una reforma fiscal que permita el pago de los impuestos con mayor equidad y proporcionalidad coadyuvará a contar con mayores ingresos y desarrollará mayor competitividad de los estados.

\section{RESULTADOS}

La perspectiva económica para México según estudios realizados por calificadoras como Moody's, Satandar\&Poor's o JP Morgan empresas internacionales miden el riesgo soberano y la deuda entre otros aspectos de un país auguran calificaciones a la baja para México en los próximos meses. Lo anterior, debido a decisiones gubernamentales que han afectado la economía del país tales como la cancelación del nuevo aeropuerto que llevaba un avance del $40 \%$, el rescate de Pemex con un monto muy inferior al esperado y con reglas de operación no claras.

Por otra parte, los efectos de la pandemia, los niveles de inseguridad, la guerra comercial entre EUA y China, la volatilidad de los mercados y los problemas migratorios han afectado el crecimiento económico del país. En este sentido, la Secretaría de Hacienda y Crédito Público dio a conocer que México tendrá un menor crecimiento en 2019 de un $2 \%$ hasta un $1.6 \%$ y en 2020 a $1.9 \%$ lo que implica el cambio de políticas públicas como la fiscal, para garantizar la competitividad empresarial.

Sin duda el análisis de competitividad es una herramienta importante para la toma de decisiones en cualquier ámbito. Sin embargo, hay que llevar a cabo este tipo de estudios de manera transparente y objetiva considerando las múltiples variables que pueden indicar el 
nivel de competencia de un país.

Uno de los indicadores más relevantes en este sentido, es el índice de competitividad Internacional (ICI) el cual mide la capacidad de las economías más importantes del mundo para generar, atraer y retener talento e inversión que se traduzcan en mayor productividad y bienestar para sus habitantes. El índice mide a 43 países, 10 subíndices y 129 indicadores a través de los cuales se evalúan distintas dimensiones de competitividad según el índice de Competitividad Internacional (2017) México ocupaba el lugar 36 de los 43 países. Por otro lado, en el índice de competitividad global México se encuentra en la posición 46 del ranking de competitividad mundial de 140 países analizados en este indicador se mide de qué manera utiliza un país los recursos y la capacidad de proveer a sus habitantes un alto nivel de prosperidad.

En 2018 México se ubicó en el lugar 54 de 190 en la clasificación mundial que mide la facilidad para hacer negocios del reporte (Doing Business, 2019), elaborado por el Grupo Banco Mundial. Esta posición lo ubica como el país más competitivo para hacer negocios en América Latina y de los más competitivos entre las economías en desarrollo. Sin embargo, en el segundo trimestre del 2019 la situación no ha sido la favorable por lo que se tienen que tomar medidas importantes en la política pública y fiscal para afrontar los embates de una economía en desaceleración, gran volatilidad de los mercados y las decisiones políticas del gobierno.

Asimismo, dicho reporte hace mención que México ha mantenido su competitividad por la implementación de estrategias para facilitar el inicio de un nuevo negocio, protección a los inversionistas, acceso a créditos y facilidad en las actividades de comercio exterior. En la figura 2 se observa el comportamiento del Ranking e índice de competitividad de México desde el año 2010 al 2018 elaborado por Foro Económico Mundial (WEF) el cual mejoró al tener la posición 44 en el año 2017 con 63.43 puntos y subir dos niveles en el año 2018 al lugar 46 de 140 países analizados con 64.6 puntos. Sin embargo, el ranking de competitividad bajó de
51 en el año 2017 a 46 en el 2018. Cabe señalar que México en el 2019 ocupó la posición 48 con 64.9 puntos de un total de 100 puntos. Sin embargo, para el 2020 no hay reportes aún, por lo que se considerarán los informes de competitividad de las entidades realizado por el Instituto Mexicano de Competitividad.

Según los resultados de los indicadores, México aún se considera una economía fuerte y estable para los inversionistas en un entorno donde la economía mundial se encuentra en desaceleración económica. Sin embargo, hay que estar atentos a los cambios del entorno mundial y político ya que las perspectivas de crecimiento no serán las planeadas por lo que se requieren de cambios estratégicos en la política pública y fiscal para hacer frente a los problemas venideros.

En materia de ingresos presupuestarios México cuenta con buenos indicadores a pesar del entorno en la tabla 1 se muestra el ingreso del primer trimestre del 2021 con un total de 1 billón 564 mil 71 millones de pesos con un incremento de 42 mil 601 millones representando un incremento del 2.8 en términos reales.

En cuanto a los ingresos en materia de contribuciones, también se muestran datos favorables a pesar del efecto de la pandemia. La estrategia de fiscalización ha funcionado positivamente para la federación contribuyendo a tener finanzas públicas sanas. La tabla 2 muestra el comportamiento de los ingresos por concepto de las contribuciones reales que tuvo la federación en los últimos cinco años. Se puede observar en promedio de los cinco años un incremento promedio del $5 \%$ y específicamente del 2019 al 2020 el incremento porcentual fue del $4 \%$. Lo anterior, obedece al incremento de la base de contribuyentes activa derivada de la estrategia de la política hacendaria y los efectos de la pandemia al disminuir la actividad económica de varios sectores.

Es importante hacer mención que los impuestos federales tales como el Impuesto sobre la Renta (ISR), el Impuesto al Valor Agregado (IVA) y el Impuesto sobre Producción y Servicios (IEPS) son los principales rubros por los que el gobierno obtiene ingresos para hacer frente a los 
servicios que demanda la ciudadanía. Aunque la tendencia ha sido al alza, es importante mencionar que según la OCDE México se encuentra en los últimos lugares en la recaudación de impuestos en relación con el PIB siendo este de sólo el $16.2 \%$ y comparándolo con el promedio de este organismo que fue del $34.2 \%$; indicador que lo ubica situación desfavorable y que tiene que ser atendida en una política hacendaria que permita atacar los niveles de informalidad y evasión de impuestos.

Un dato importante es la dependencia que ha perdido México de los ingresos petroleros, tal como se puede percibir en la figura 3. Los ingresos del sector público en relación con el PIB en los últimos cuatro años dependen en gran medida de los impuestos y no de los ingresos petroleros lo que se puede considerar bueno en un entorno donde la situación económica que vive la para estatal no es la óptima.

La política hacendaria de la SHCP ha permitido conservar los índices de competitividad favorables para México. Sin embargo, se tienen grandes retos para mejorar los niveles de recaudación y ser más justos y equitativos con los desiguales, es decir, que paguen impuestos los que más ganan. Además, en materia fiscal México tiene celebrados acuerdos para evitar la doble tributación con países de todas las regiones del mundo lo que permite fortalecer las relaciones comerciales y de inversión.

Actualmente en México las personas morales causan un $40 \%$ global, $30 \%$ en su operatividad y $10 \%$ definitivo al pago de dividendos y las personas físicas tienen una tasa de hasta el $35 \%$ por su actividad realizada. $\mathrm{Al}$ perecer por un lado las finanzas públicas son sanas derivado de una política hacendaria que permitió equilibrar los gastos con los ingresos y no incrementar los impuestos. Sin embargo, de acuerdo con el estudio realizado por el Instituto Mexicano para la Competitividad (IMCO, 2021) se observa en la tabla 3 el total de las entidades y la agrupación. Es importante mencionar, que el índice se conforma por 72 indicadores que forman 10 subíndices y mide la capacidad de las entidades para generar, atraer y retener el talento e inversiones (ICE 2021) y la clasificación es en función a 6 grupos de competitividad. En este sentido, se observa que sólo una entidad se encuentra en el nivel más alto siendo la Ciudad de México, en cambio 10 de las entidades se encuentra clasificada en la agrupación media alta, 11 en la media baja y 6 en baja. Lo anterior, permite reflexionar sobre la situación precaria que viven los ciudadanos de por lo menos 17 entidades considerando la agrupación media baja y baja del índice de competitividad.

Además, es importante señalar que el índice de competitividad promedio de las 32 entidades se ubica en 45.64 de 100 puntos según la metodología aplicada por el IMCO. También, en promedio todas las entidades empeoraron su crecimiento del PIB pasando del $1.2 \%$ al $-2.3 \%$. En este sentido se puede concluir que existen grades extremos entre diversas entidades; las entidades más competitivas que se ubican en los dos primeros grupos, cuentan en promedio con 8 años de escolaridad siendo el promedio general de 7.9 de todas las entidades, el $52 \%$ de los trabajadores tienen acceso a instituciones de salud y en promedio de las 32 entidades es de $40 \%$, el $41 \%$ de los trabajadores son informales y el promedio general es del $54 \%$, el ingreso mensual promedio es de $\$ 8,972$ mientras que el promedio general es de $\$ 7,456$.

\section{CONCLUSIONES}

En un entorno económico mundial desfavorable por varios factores, principalmente por la pandemia, la desaceleración económica, la guerra comercial entre EUA y China, la volatilidad de los mercados financieros y los problemas de migración que vive México. Es indispensable mantener una política hacendaria prudente a través de una disciplina en el gasto público. Por lo tanto, se debe seguir mejorando la eficiencia recaudatoria y reducir las exenciones y gastos tributarios. Una mayor progresividad del impuesto sobre la renta individual mejoraría la escasa recaudación de impuestos y la equidad.

Aunque México ha presentado incrementos en la recaudación de impuestos 
por la implementación de una política hacendaria no deja de tener graves problemas de informalidad y competitividad en la economía según datos de la OCDE, que repercuten en una baja recaudación en comparación con los países miembros de dicho organismo.

En niveles de competitividad México en el año 2019 mejoró su posición con respecto al año 2018 ocupando el lugar 48 de 140 países según datos del Foro Económico Mundial. Situación que permite ver con buenos ojos a México para la inversión extranjera. Sin embargo, muchos de los datos son previos a la pandemia, por lo tanto, los resultados que arrojó el reporte elaborado el Instituto Mexicano para la Competitividad en el 2021 para todas las entidades muestran resultados no muy favorables en términos generales ubicándose el índice de competitividad en promedio de 45.64 de un total de 100 puntos.

En este sentido, se puede concluir que por un lado los esquemas de fiscalización y la política hacendaria han contribuido a contar con finanzas públicas sanas y por otra parte se los niveles de competitividad no son los ideales para posicionar a la economía fuerte en términos de inversión, innovación, reformar las leyes de adquisición y de obra pública para eficientar la ejecución de obras y compras en tiempos de emergencia, un estado de derecho que de certidumbre a las modificaciones presupuestales de los poderes ejecutivos estatales y una mayor vinculación con las universidades con el afán de desarrollar programas de nivelación académica y reincorporación de los alumnos.

En cuanto a la política hacendaria el reto es realizar reformas fiscales y estrategias que permitan seguir incrementando la base de contribuyentes, incorporado a todos aquellos que están en la informalidad. Para ello, se propone una estrategia de simplificar el marco normativo para facilitar la inscripción de contribuyentes, disminuir del $10 \%$ al $8 \%$ la tasa de ISR sobre a utilidad obtenida a partir del próximo 2022 y en el Régimen de Incorporación Fiscal continuar apoyando con el estímulo del IVA al $100 \%$, el $50 \%$ de estímulos a cargo del impuesto de ISR y los impuestos locales por lo menos en los tres años posteriores a la pandemia y de forma gradual quitando el estímulo por año en un $10 \%$

Por otra parte, realizar censos físicos por parte del municipio en función al padrón de negocios que pagan derecho de uso de suelo $y$ licencia de funcionamiento $y$ que posiblemente no estén inscritos en la federación. Esto incrementaría la recaudación de impuestos tanto directos como indirectos.

También, es importante hacer una restructuración en disminuir las tarifas que pagan los asalariados por concepto de ISR incrementando la liquidez de los trabajadores quienes dispondrán de dinero para efectuar más gasto en beneficio de las familias. De esta forma estaríamos hablando de una equidad impositiva más justa, teniendo un efecto de mayor productividad en la economía.

Un punto importante reducir a un $25 \%$ la tasa de ISR y la creación de un $10 \%$ de un impuesto empresarial para la inversión en ciencia, tecnología e innovación, que sería el equivalente a un impuesto sobre la renta corporativo.

Además, es importante generar la normatividad para regular en el aspecto fiscal a las inversiones en criptomonedas, a través del reconocimiento de la compra de dichos activos virtuales y el establecimiento de una tasa fija de retención en beneficio del emisor y de los inversionistas que hasta el momento se encuentran en gran riesgo.

Es importante señalar que los indicadores de competitividad y algunos reportes de organismos internacionales son resultado de ejercicios anteriores al 2020. Sin embargo, otros estudios ya analizados muestran la perspectiva económica y fiscal que se espera para los meses consecutivos, situación que no es la óptima para la economía mexicana.

Sin duda, existen grandes retos para el gobierno federal en aras de mantener una economía estable que garantice un mejor bienestar social y una mayor competitividad de las empresas. Por lo que es necesaria la implementación de una política hacendaria que coadyuve a terminar con este flagelo conocido como economía informal y hacer más justo el pago de impuestos. 


\section{REFERENCIAS}

Annoni, P. y Kozovska K. (2010), EU Regional Competitiveness Index 2010, European Commission, 
Joint Research Centre, eur24346en-2010.

Corona, L. (2011). "Innovación y competitividad empresarial." Aportes. Revista de la Facultad de Economía, Benemérita Universidad Autónoma de Puebla, año 2 (20)

Chamley, C. (1986): "Optimal taxation of capital income in general equilibrium with infinite lives", Econometrica 54, pp. 607-622.

Huber B., G., \& Mungaray L., A. (2017). Los índices de competitividad en México. Gestión y Política Pública, 26(1), 167-218. Retrieved from http://search.ebscohost.com/login.aspx ?direct=true \&db=a9h\&AN=124732264\&lang=es\&site= ehost-live

Inzunza, M., Sánchez, D., Armando J., Disciplina fiscal: límites de la política hacendaria para promover el desarrollo en México. Nóesis. Revista de Ciencias Sociales y Humanidades [en linea] 2013, 22 [Fecha de consulta: 22 de junio de 2019] Disponible en: <http://www.redalyc.org/articulo.oa?id=85927874006> ISSN 0188-9834

Instituto Nacional de Estadística y Geografía (INEGI). Consultado el 27-05-2021. https://www.inegi.org.mx/contenidos/saladeprensa/boletines/2021/pib_eo/pib_eo2021_01.pdf

Martínez A. L. y Torres L. M. (2017). Índice de competitividad internacional 2017. Instituto Mexicano para la Competitividad. Recuperado de: https://api.imco.org.mx/release/latest/vendor/imco/indices-api/documentos/Competitividad

Ortiz, D. (2014) Política hacendaria y monetaria. Recuperado de: http://www.academia.edu/10100746/POL\%C3\%8DTICA_FISCAL_Y_MONETARIA. Fecha de consulta: Mayo 2021.

Organización para la Cooperación y Desarrollo Económicos (OCDE). Consultado el 24-05-2021. https://doi.org/10.1787/edfbca02-en. Pinzón B., Dary, L., Internacionalizción y Competitividad. Revista Ciencias Estratégicas [en linea] 2014, 22 (Julio-Diciembre): [Fecha de consulta: 25 de junio de 2019] Disponible en:<http://www.redalyc.org/articulo.oa?id=151339264001> ISSN $1794-8347$

Rudiger, Dornbusch y Fischer S. (1995) Curso breve de macroeconomía, Madrid. Ed. McGraw-Hill. Serrano (2019). Política hacendaria con señales positivas. El financiero. Consultado en: https://www.elfinanciero.com.mx/opinion/carlos-serrano-herrera/politica-fiscal-con-senalespositivas.

Secretaría de Hacienda y Crédito Público (2021). Recuperado de: https://www.finanzaspublicas.hacienda.gob.mx/es/Finanzas_Publicas/Paquete_Economico_y_P resupuesto

UNAM (2012) Elementos del Sistema Tributario Mexicano. Marco Institucional. Recuperado de: http://www.economia.unam.mx/secss/docs/tesisfe/BonillaLI/cap2. Fecha de consulta: marzo 2017. 
Figura 1. Proyección de la Ley de Ingresos de la Federación

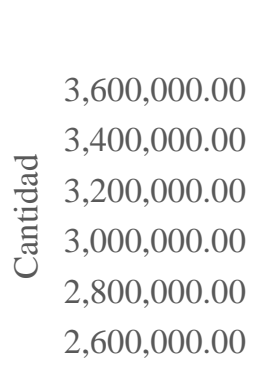

Ingresos estimado en millones de pesos por impuestos

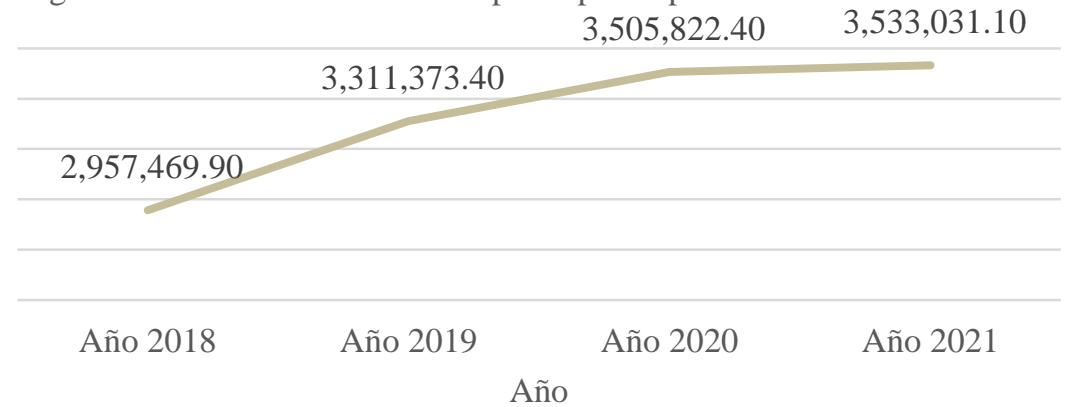

$\longrightarrow$ Año $2018 \longrightarrow$ Año $2019 \longrightarrow$ Año $2020 \longrightarrow$ Año 2021

Fuente: Elaboración propia con datos de la Ley de ingresos de la Federación de cada año.

Figura 2. Índice de competitividad

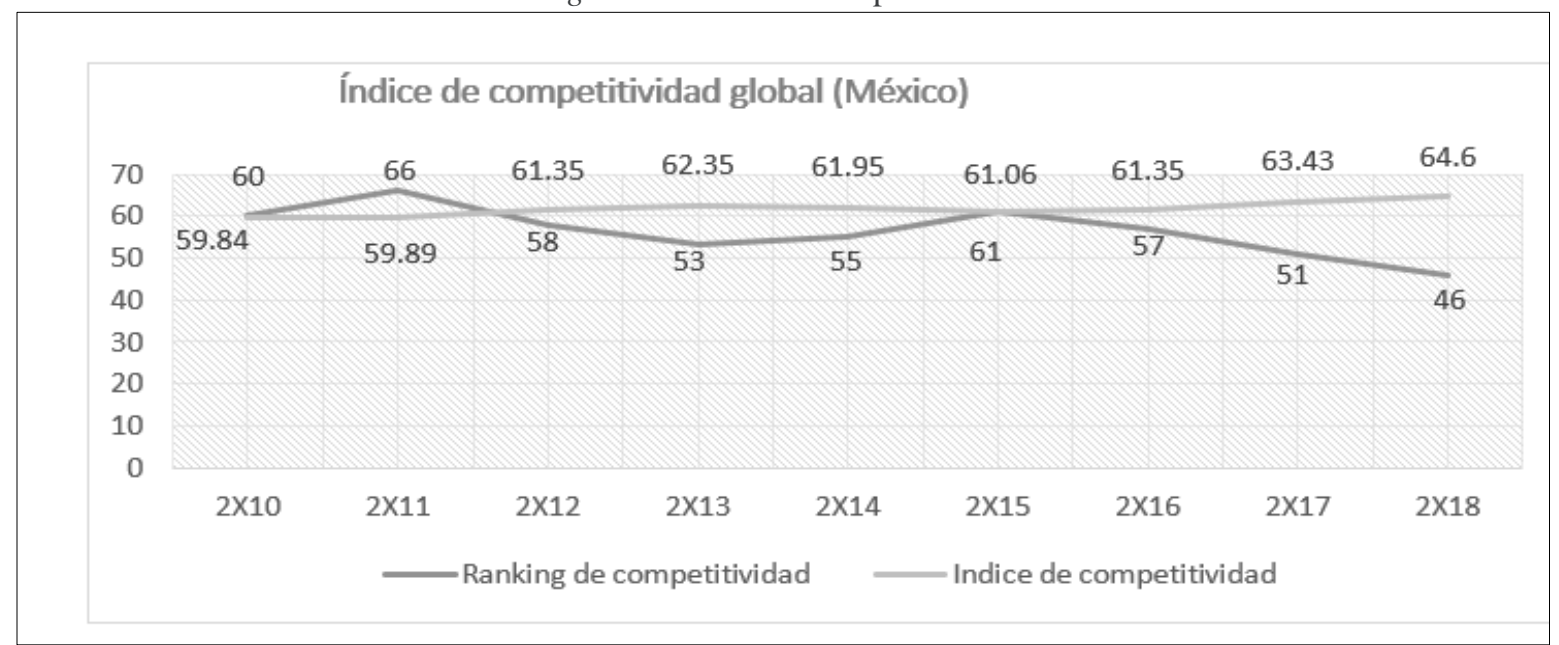

Fuente: Elaboración propia con datos del Foro Económico Mundial (WEF).

Tabla 1. Ingresos del sector público presupuestario

(Millones de pesos)

\begin{tabular}{lcccc}
\hline \multicolumn{1}{c}{ Concepto } & Enero- marzo 2020 & Enero - marzo 2021 & $\begin{array}{c}\text { Diferencia } \\
\text { variación \% } \\
\text { real }\end{array}$ & $\begin{array}{c}\text { \% } \\
\text { Ingresos }\end{array}$ \\
$\begin{array}{l}\text { presupuestarios } \\
\text { Fuente: Elaboración propia con datos del informe sobre finanzas públicas 1T2021. }\end{array}$ & $1,521,469.46$ & $42,601.14$ & $2.80 \%$ \\
\cline { 4 - 5 }
\end{tabular}

Tabla 2. Ingresos tributarios reales

(cifras en millones de pesos) 


\begin{tabular}{ccc}
\hline AÑO & $\begin{array}{c}\text { Total de ingresos } \\
\text { tributarios }\end{array}$ & $\begin{array}{c}\text { Incremento } \\
\text { porcentual }\end{array}$ \\
\hline Año 2016 & $2,716,219.11$ & \\
\hline Año 2017 & $2,849,528.67$ & $5 \%$ \\
\hline Año 2018 & $3,062,334.01$ & $7 \%$ \\
\hline Año 2019 & $3,202,650.72$ & $5 \%$ \\
\hline Año 2020 & $3,338,943.08$ & $4 \%$ \\
\hline
\end{tabular}

Fuente: Elaboración propia con datos del Servicio de Administración Tributaria 2021.

Figura 3. Tendencia de los ingresos del sector público

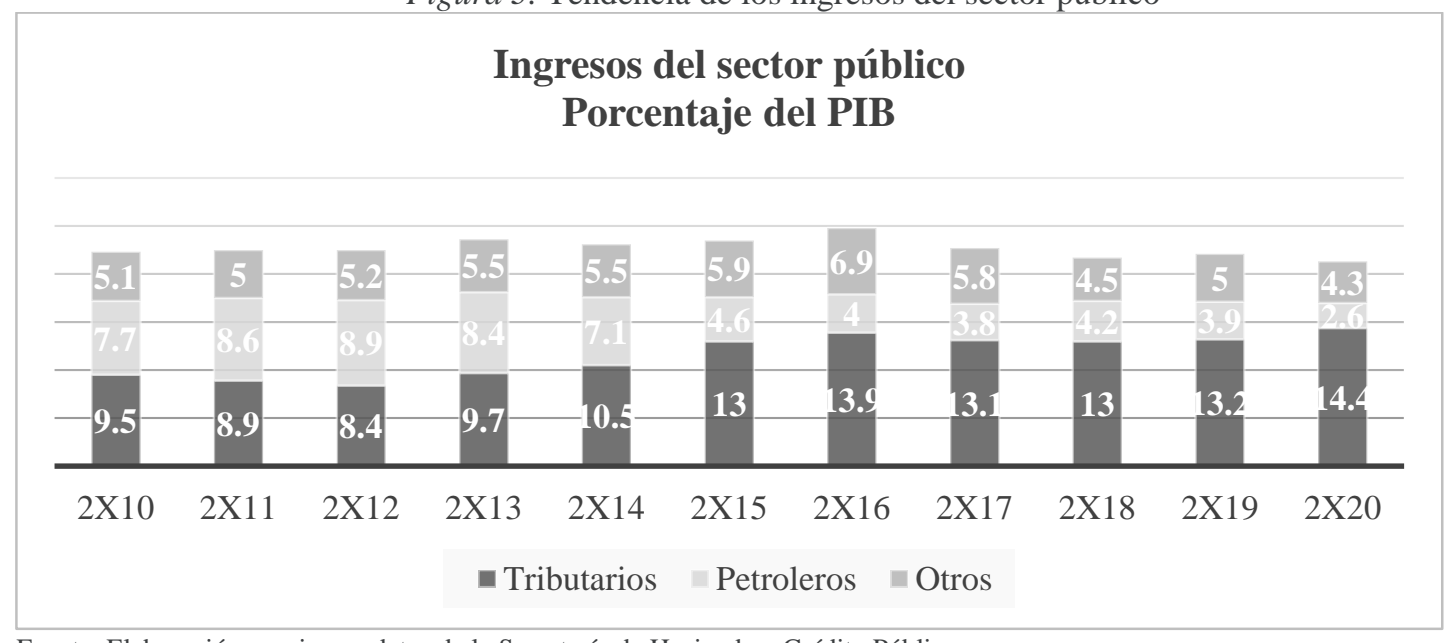

Fuente: Elaboración propia con datos de la Secretaría de Hacienda y Crédito Público

Tabla 3. Número de entidades por grupo de competitividad

\begin{tabular}{lcc}
\hline Grupo de competitividad & Número de entidades & Porcentaje \\
\hline Alta & 1 & $3.13 \%$ \\
\hline Adecuada & 4 & $12.50 \%$ \\
\hline Media alta & 10 & $31.25 \%$ \\
\hline Media Baja & 11 & $34.38 \%$ \\
\hline Baja & 6 & $18.75 \%$ \\
\hline Muy baja & 0 & $0.00 \%$ \\
\hline Total de entidades & 32 & $100.00 \%$
\end{tabular}

Fuente: Elaboración propia con datos del Índice de Competitividad Estatal 2021. 